\title{
Emergence of Orientation Selectivity in the Mammalian Visual Pathway
}

\author{
Benjamin Scholl, Andrew Y. Y. Tan, Joseph Corey, and Nicholas J. Priebe \\ Center for Perceptual Systems, Section of Neurobiology, School of Biological Sciences, College of Natural Sciences, The University of Texas at Austin, \\ Austin, Texas 78712
}

Orientation selectivity is a property of mammalian primary visual cortex (V1) neurons, yet its emergence along the visual pathway varies across species. In carnivores and primates, elongated receptive fields first appear in V1, whereas in lagomorphs such receptive fields emerge earlier, in the retina. Here we examine the mouse visual pathway and reveal the existence of orientation selectivity in lateral geniculate nucleus (LGN) relay cells. Cortical inactivation does not reduce this orientation selectivity, indicating that cortical feedback is not its source. Orientation selectivity is similar for LGN relay cells spiking and subthreshold input to V1 neurons, suggesting that cortical orientation selectivity is inherited from the LGN in mouse. In contrast, orientation selectivity of cat LGN relay cells is small relative to subthreshold inputs onto V1 simple cells. Together, these differences show that although orientation selectivity exists in visual neurons of both rodents and carnivores, its emergence along the visual pathway, and thus its underlying neuronal circuitry, is fundamentally different.

\section{Introduction}

In every mammal for which the neuronal response selectivity of primary visual cortex (V1) has been examined, orientation selectivity has been observed. In cat V1, where orientation selectivity was first described, thalamic lateral geniculate nucleus (LGN) relay cells are characterized by circularly symmetric receptive fields, whereas their postsynaptic cortical targets display elongated receptive fields, endowing V1 neurons with a selectivity for stimulus orientation not present in the LGN (Hubel and Wiesel, $1959,1962)$. It was this dramatic change in receptive field properties that led Hubel and Wiesel to propose a simple feedforward model in which multiple spatially offset LGN relay cells with circularly symmetric receptive fields converge onto a single V1 neuron to generate elongated receptive fields (Hubel and Wiesel, 1962) (see Fig. 1A). The ubiquity of orientation selectivity across mammals has also led to it being considered a canonical cortical computation (Douglas et al., 1989; Douglas and Martin, 2004). Although the recent advent of rodent models allows for dissection of neural circuitry using genetic techniques, it remains unknown whether these species demonstrate this canonical transformation between the LGN and V1.

Orientation selectivity is present in mouse V1, albeit to a weaker degree than that found in the cat (Dräger, 1975; Wagor et al., 1980; Métin et al., 1988; Sohya et al., 2007; Niell and Stryker, 2008; Kerlin et al., 2010; Runyan et al., 2010; Tan et al., 2011; Li et

\footnotetext{
Received Jan. 28, 2013; revised April 29, 2013; accepted May 12, 2013.

Author contributions: B.S. and N.J.P. designed research; B.S., A.Y.-Y.T., J.C., and N.J.P. performed research; B.S., A.Y.-Y.T., and N.J.P. analyzed data; B.S. and N.J.P. wrote the paper.

This work was supported by the National Institutes of Health Grant EY-019288 and The Pew Charitable Trusts. We thank Jessica Hanover for helpful discussions and comments.

The authors declare no competing financial interests.

Correspondence should be addressed to Nicholas J. Priebe, Section of Neurobiology, The University of Texas at Austin, 2400 Speedway, Austin, TX 78712.E-mail: nicholas@mail.utexas.edu.

DOI:10.1523/JNEUROSCI.0404-13.2013

Copyright $\odot 2013$ the authors $\quad 0270-6474 / 13 / 3310616-09 \$ 15.00 / 0$
}

al., 2012). It is unclear, however, the degree to which cortical orientation selectivity in rodents reflects processing occurring within V1 (Fig. 1A), or the inheritance of response selectivity from subcortical structures (Fig. 1B). Evidence for subcortical orientation selectivity has been observed in lagomorphs, where strong retinal orientation and direction selectivity are observed (Barlow et al., 1964; Levick, 1967), and in carnivores, where orientation biases have been associated with systematic asymmetries of retinal ganglion cell arbors (Boycott and Wässle, 1974; Cleland and Levick, 1974; Hammond, 1974; Levick and Thibos, 1980; Leventhal and Schall, 1983; Shou et al., 1995). Orientation selectivity has also been observed in the LGN of rodents (Marshel et al., 2012; Piscopo et al., 2013) and marmosets (Cheong et al., 2013), although the relationship between this selectivity and that found in V1 is unknown. Subcortical orientation biases could therefore play a role in the generation of cortical orientation selectivity and work in conjunction with the Hubel and Wiesel framework (Fig. 1C).

To uncover the origin of orientation selectivity observed in rodent V1 we compared orientation selectivity of single neurons in mouse LGN and V1. In mouse, we find a similar degree of orientation selectivity among LGN relay cells as the subthreshold input to V1 neurons. Inactivating cortex did not eliminate orientation selectivity in LGN relay cells. In contrast to the mouse, orientation selectivity in cat increases between the LGN and V1. Our data demonstrate that orientation selectivity is dramatically enhanced between the LGN and cortex in the cat but not the mouse. It is evident that the organization of visual processing, and thus the underlying circuitry, differs between these two mammals.

\section{Materials and Methods}

Physiology. Physiological procedures for mouse recordings were based on those previously described (Tan et al., 2011). All of our experiments were conducted using adult C57BL/6 mice (age 5-8 weeks). Both male and female animals were used. Mice were anesthetized with intraperitoneal injection of either $50-80 \mathrm{mg} / \mathrm{kg}$ sodium pentobarbital $(n=20)$ or $1 \mathrm{~g} / \mathrm{kg}$ 
A

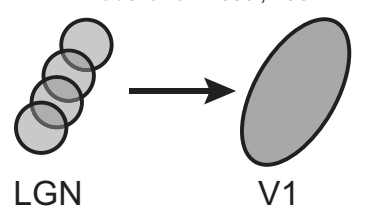

B

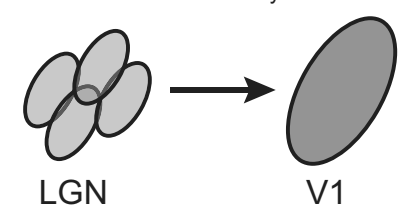

C

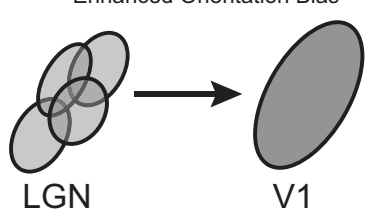

Figure 1. Models of the emergence of cortical orientation selectivity. $A$, Spatially offset $L G N$ relay cells are combined to generate orientation selectivity in a Hubel and Wiesel framework (Hubel and Wiesel, 1962). B, Cortical orientation selectivity could be inherited from subcortical structures. $C$, Orientation bias of relay cells could generate orientation selectivity in combination with a Hubel and Wiesel framework.

urethane $(n=26)$ and with intramuscular injection of $10 \mathrm{mg} / \mathrm{kg}$ chlorprothixene; the dose of sodium pentobarbital or urethane was adjusted during the procedure to eliminate the pedal withdrawal reflex. Brain edema was prevented by intraperitoneal injection of $20 \mathrm{mg} / \mathrm{kg}$ dexamethasone. Animals were warmed with a thermostatically controlled heat lamp to maintain body temperature between $37-38^{\circ} \mathrm{C}$. A tracheotomy was performed. The head was placed in a mouse adaptor (Stoelting) and a craniotomy and duratomy were performed over visual cortex. Eyes were kept moist with either frequent application of artificial tears or a thin layer of silicone oil.

The physiological procedures for cat experiments were based on those previously described (Tan et al., 2011). Only female animals were used. Briefly, anesthesia was induced with ketamine $(5-15 \mathrm{mg} / \mathrm{kg}$ ) and acepromazine $(0.7 \mathrm{mg} / \mathrm{kg})$, followed by intravenous administration of a mixture of propofol and sufentanil. Once a tracheotomy was performed the animal was placed in a stereotaxic frame for the duration of the experiment. Recording stability was increased by suspending the thoracic vertebrae from the stereotactic frame and performing a pneumothoracotomy. Eye drift was minimized with intravenous infusion of vecuronium bromide. Anesthesia was maintained during the course of the experiment with continuous infusion of propofol and sufentanil (6-9 $\mathrm{mg} / \mathrm{kg} / \mathrm{h}$ and $1-1.5 \mu \mathrm{g} / \mathrm{kg} / \mathrm{h}$, respectively). Body temperature, electrocardiogram, EEG, $\mathrm{CO}_{2}$, blood pressure, and autonomic signs were continuously monitored and maintained. The nictitating membrane was retracted using phenylephrine hydrochloride and the pupils were dilated using topical atropine. Contact lenses were inserted to protect the corneas. Supplemental lenses were selected by direct ophthalmoscopy to focus the display screen onto the retina.

Extracellular recordings. Extracellular electrodes (1-2 M $\Omega$, Micro Probes) were advanced into cortex (cat: area 17, $\sim 2 \mathrm{~mm}$ lateral of midline; mouse: V1 binocular zone) or into the LGN (cat: $9 \mathrm{~mm}$ lateral of midline and $6 \mathrm{~mm}$ anterior; mouse: $2.5 \mathrm{~mm}$ posterior of bregma and $2 \mathrm{~mm}$ lateral of midline) with a motorized drive (MP-285, Sutter Instrument). After the electrode was in place, warm agarose solution ( $2-4 \%$ in normal saline) was placed over the craniotomy to protect the surface of the cortex and reduce pulsations. V1 was located and mapped by multiunit extracellular recordings with parylenecoated tungsten electrodes (Micro Probe). In mouse, the boundaries of V1 and V2 were identified by the characteristic gradient in receptive field locations (Dräger, 1975; Wagor et al., 1980; Métin et al., 1988). Mouse LGN was consistently in the same location and at a depth of 2.2-2.8 $\mathrm{mm}$ (Grubb and Thompson, 2003). Before reaching mouse LGN, the electrode passed through cortical activity, two layers of hippocampal activity, and a quiet space (100-300 $\mu \mathrm{m}$ in depth) (Grubb and Thompson, 2003). Weak and unreliable visual responses indicated that the electrode was located medial of the LGN (Grubb and Thompson, 2003). In some experiments, the retinotopic gradient of mouse LGN could be mapped using multiunit activity. In cat, LGN recordings were restricted to layers A and A1. X and Y cells were distinguished by presenting contrast reversing gratings at a spatial frequency higher than the cutoff for drifting gratings (Hochstein and Shapley, 1976). Neurons with a frequency doubling response were labeled Y-cells, and those without were labeled X-cells. In cat V1, recordings were restricted to simple cells between 500 and 1100 micrometers deep. Action potentials were identified using a dual window discriminator (Bak Electronics, DDIS-1). The time of action potentials as well as the raw extracellular traces were recorded for later analysis.
Intracellular recordings. Glass patch electrodes (5-10 $\mathrm{M} \Omega$ ) filled with a potassiumgluconate-based solution were used to record from neurons in the whole-cell configuration. Raw membrane potential records were split into two channels: the subthreshold responses that resulted after first removing the action potentials using a median filter; the suprathreshold action potentials identified by the characteristic large amplitude changes in membrane potential.

Stimuli. Visual stimuli were generated by a Macintosh computer (Apple) using the Psychophysics Toolbox (Brainard, 1997; Pelli, 1997) for MATLAB (MathWorks) and presented using Sony video monitors (GDM-F520) placed either $50 \mathrm{~cm}$ (cat) or $38 \mathrm{~cm}$ (mouse) from the animal's eyes. The video monitors had a noninterlaced refresh rate of $100 \mathrm{~Hz}$ and a spatial resolution of $1024 \times 768$ pixels, which subtended $40 \times 30 \mathrm{~cm}(58 \times 46 \mathrm{deg}$ in mouse, $44 \times 34 \mathrm{deg}$ in cat $)$. The video monitors had a mean luminance of $40 \mathrm{~cd} / \mathrm{cm}^{2}$. Drifting gratings (mouse LGN extracellular: square wave $(n=24)$ and sinusoidal $(n=48)$, mouse V1 extracellular: square wave $(n=19)$ and sinusoidal $(n=26)$, mouse V1 intracellular and cat recordings: sinusoidal) were presented for either $1.5 \mathrm{~s}$ (mouse) or $4 \mathrm{~s}$ (cat), preceded and followed by $250 \mathrm{~ms}$ blank (mean luminance) periods. Spontaneous activity was measured with blank periods interleaved with drifting grating stimuli and lasting the same duration (1.5-2 or $4 \mathrm{~s}$ ). Stimulus duration was typical for measurements in mouse (Grubb and Thompson, 2003; Niell and Stryker, 2008; Gao et al., 2010) and cat (Priebe, 2008). Spatial and temporal frequencies were optimized for each recording. In mouse, spatial frequencies used were $0.03-0.05$ cycle per degree and temporal frequencies used were $2-4 \mathrm{~Hz}$. In cat, spatial frequencies used were $0.25-1.5$ cycle per degree and temporal frequencies used were $2-4$ $\mathrm{Hz}$. Spatial frequencies used to stimulate mouse neurons were low, but are close to typical values of selectivity (Niell and Stryker, 2008). For each record we chose the spatial frequency evoking the strongest response. For a subset of neurons, we also mapped receptive fields by presenting a 2-D array of dark or light spots in a random sequence and measuring evoked responses. Spots were presented for $150-300 \mathrm{~ms}$ and were separated by $150-300 \mathrm{~ms}$. All stimuli were presented to the contralateral eye and pseudo-randomly interleaved.

Analysis. Spiking responses for each stimulus were cycled-averaged across trials after removing the first cycle. The Fourier transform of mean cycle-average responses was used to calculate the mean $\left(\mathrm{F}_{0}\right)$ and modulation amplitude $\left(\mathrm{F}_{1}\right)$ of each cycle-averaged response, after mean spontaneous activity was subtracted. Each neuron analyzed passed a visual response criterion based on an ANOVA between spontaneous firing rate during blank periods and visual stimuli (Gao et al., 2010). Simple and complex cells were separated by computing the modulation ratio $\left(\mathrm{F}_{1} / \mathrm{F}_{0}\right)$ to the preferred monocular stimulus; those neurons with modulation ratios larger than 1 are considered simple. Peak responses were defined as the sum of the mean and modulation $\left(\mathrm{F}_{0}+\mathrm{F}_{1}\right)$. Peak responses across orientations $(\Theta)$ were fit with two Gaussian curves of the same variance $\left(\sigma^{2}\right)$, but two different amplitudes $\left(\mathrm{A}_{1}\right.$ and $\left.\mathrm{A}_{2}\right)$ :

$$
R(\Theta)=\frac{A_{1}}{\sqrt{2 \pi \sigma^{2}}} e^{\frac{\left(\Theta-\Theta_{\text {pref }}\right)^{2}}{2 \sigma^{2}}}+\frac{A_{2}}{\sqrt{2 \pi \sigma^{2}}} e^{\frac{\left(\Theta-\Theta_{\text {pref }}+\pi\right)^{2}}{2 \sigma^{2}}}+D C .
$$

The second Gaussian $\left(A_{2}\right)$ was constrained to be $180^{\circ}$ phase-shifted from the preferred orientation $\left(\Theta_{\text {pref }}\right)$. A DC component was also included for cells with high spontaneous firing rates. Gaussian fits were used only for qualitative quantification of orientation tuning curves.

Orientation preference was calculated based on the vector average of the peak responses across orientations. For sparse noise maps, the average spiking response was measured for each white $(\mathrm{ON})$ and black (OFF) pixel. Spikes were averaged within the time window of the stimulus presentation (150-300 ms). A difference receptive field map (ON subtracted by OFF responses) was generated and the 2-D Fourier transform was used to recover the average direction across the first and second spatial frequency amplitude components (Gardner et al., 1999). 
Statistics. All summary statistical significances were calculated using the Mann-Whitney-Wilcoxon rank sum test for equal medians unless stated otherwise. A bootstrapped principle component analysis was used to calculate relationships of measured quantities (Sokal and Rohlf, 1995). Confidence intervals on orientation selectivity and direction selectivity were also computed with a bootstrap to quantify significance and measure response noise (Sokal and Rohlf, 1995). Bootstrap analyses were performed using all stimulus trials for each neuron, running 10,000 iterations and sampling with replacement.

All procedures were approved by The University of Texas at Austin Institutional Animal Care and Use Committee.

\section{Results}

\section{Orientation selectivity in mouse LGN}

We measured orientation selectivity in relay cells of mouse LGN using extracellular single-unit recordings in anesthetized animals. We first verified our location within the LGN (see Materials and Methods) and then isolated the activity of individual neurons by separating each neuron's waveform from the surrounding multiunit activity. We measured the neuron's orientation selectivity using drifting gratings presented to the contralateral eye of 72 LGN relay cells, of which for 18 cells we also presented dark and light spots to measure the spatial receptive field.

We observed a range of orientation selectivity across relay cells of mouse LGN. Responses of some neurons were modulated substantially by different stimulus orientations, evident both in the mean cycle-averaged spiking responses (Fig. 2A, top) and the peak (F1+ F0, see Materials and Methods) responses (Fig. $2 A$, bottom). To quantify the degree of orientation selectivity for each recorded neuron, we computed the orientation selectivity index (OSI) from the peak response to 12 orientations (Ringach et al., 2002; Tan et al., 2011):

$$
O S I=\frac{\sqrt{\left(\sum R(\Theta) \sin (2 \Theta)\right)^{2}+\left(\sum R(\Theta) \cos (2 \Theta)\right)^{2}}}{\sum R(\Theta)} .
$$

For the example LGN relay cell shown in Figure $2 A$, modest orientation selectivity in the peak response was reflected by the OSI measurement (OSI $=0.26)$. Other relay cells were modulated little by oriented gratings, evident both in their mean cycle-averaged responses and the OSI (Fig. 2B; OSI = 0.02). Although some relay cells had high firing rates and little spontaneous activity (Fig. 2A,B), we also recorded from cells with lower firing rates that were selective for orientation (Fig. 2C) or largely unmodulated by oriented gratings (Fig. 2D). A few relay cells also showed high background firing rates, such that response modulations evoked by gratings protruded from high spontaneous activity (Fig. 2D). Across the population we discovered that a modest amount of orientation selectivity was common $($ mean OSI $=0.19 \pm 0.14 \mathrm{SD}$, median OSI $=0.15, n=53)$. We include, in our sample population, relay cells for which sine and square wave gratings were used to measure orientation selectivity (sine, $n=48$; square, $n=24$ ). To be sure that using square and sine wave gratings to measure orientation selectivity does not alter our results, however, we used two additional analyses. First, we compared the median OSI between these sample populations and found no significant difference in selectivity $(p=0.31)$. Second, for a subset of relay cells, orientation selectivity was measured with both sine and square wave gratings. There was no statistical difference between OSI based on sine and square wave gratings $(n=11, p=0.51)$. For tuned LGN neurons (OSI $>0.20, n=30$ ), we also examined orientation preference to determine whether all orientations are represented equally. Despite finding a broad range of orientation preferences, there was an overrepresentation along the horizontal axis, similar to previous reports (Marshel et al., 2012; Piscopo et al., 2013). In these tuned geniculate cells, the mean tuning width from Gaussian fits (see Materials and Methods) was modest (mean $\sigma=39 \pm 22^{\circ} \mathrm{SD}$ ).

Of neurons that were orientation selective (OSI $>0.20$ ), many were biased for a particular direction. Direction selectivity was measured by comparing the preferred and opposite (null) direction responses at the same orientation to generate the direction selectivity index (DSI):

$$
D S I=\frac{R_{p}-R_{n}}{R_{p}+R_{n}} .
$$

A DSI value of 0 indicates no direction selectivity, whereas a DSI value of 1 indicates complete selectivity. For example the relay cell shown in Figure $2 C$ has a DSI of $0.89(p<0.05$, bootstrap analysis) (Sokal and Rohlf, 1995), whereas the relay cell shown in Figure $1 A$ has a DSI of 0.03 . From the 30 neurons that we assayed in mouse LGN, the average DSI was $0.46 \pm 0.25 \mathrm{SD}$, where $83 \%$ of all neurons exhibited DSI values significantly different from 0 ( $p<0.05$, bootstrap analysis) (Sokal and Rohlf, 1995).

For a subset of mouse LGN relay cells $(n=18)$ we also measured receptive field locations that responded to dark or light stimuli by presenting a slow sparse noise stimulus (Gardner et al., 1999). The receptive field properties revealed a match between the orientation selectivity measured using drifting gratings. Neurons that showed modest orientation selectivity were found to have elongated spatial configurations that matched the orientation preference (Fig. 2E). For orientation selective neurons (OSI $>0.20, n=7)$, the orientation preferences (see Materials and Methods) derived from drifting gratings and that derived from the 2-D Fourier transform of the receptive field map, were similar $(\Delta \Theta=23 \pm 32$ degrees, mean \pm SD). Therefore the orientation preference of individual mouse LGN neurons is related to the underlying spatial structure of their receptive fields. The large variability in the correspondence between orientation preference based on gratings and flashed spots, may be related to the nonlinear nature of receptive fields observed in several neurons.

\section{Contribution of cortical feedback to mouse LGN orientation selectivity}

The orientation selectivity we observed in mouse LGN could be due to feedforward input from the retina or feedback projections from excitatory V1 neurons in layer 5/6 (Sillito et al., 1994). We isolated the contribution of retinal feedforward connections to LGN response selectivity by inactivating V1 with muscimol, a $\mathrm{GABA}_{\mathrm{A}}$ receptor agonist (see Materials and Methods). While muscimol was present on the cortex, we recorded multiunit activity in layers 5/6 of V1. Shortly after muscimol application (20 min), spontaneous cortical activity was reduced; $40 \mathrm{~min}$ after muscimol application, spontaneous cortical activity ceased (Fig. $3 A$ ). Additionally, a flashing LED light was used to stimulate the contralateral eye and no visual activity could be evoked in cortex either.

Even in this absence of cortical activity, we continued to observe LGN relay cells with orientation selectivity, evident in peak responses to oriented gratings and sparse noise maps of receptive field on and off subregions (Fig. $3 B$ ). We also observed LGN relay cells with little orientation tuning (Fig. $3 C$ ), demonstrating great similarity to the population of neurons we recorded from mouse LGN without cortical application of muscimol $(n=19$, mean OSI $=0.22 \pm 0.17 \mathrm{SD}$, median $=0.14$ ). There was no statistical difference in mean OSI between LGN relay cells recorded with or without cortical inactivation $(p=0.57)$. These data demonstrate that the orientation selectivity evident in relay cells of the mouse 
A

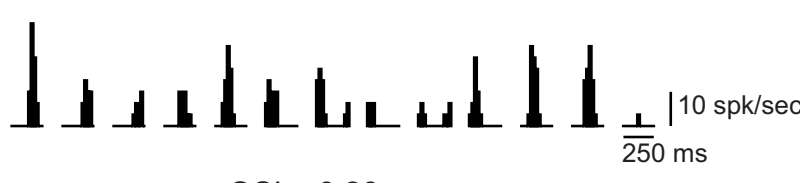

$\mathrm{OSI}=0.26$
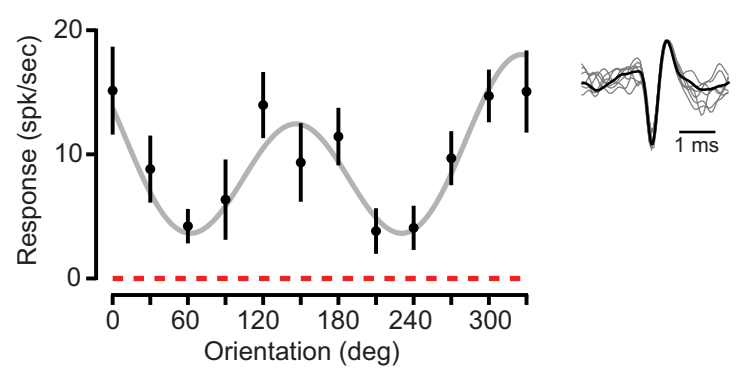

B

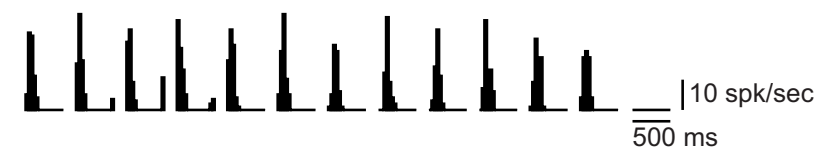

$\mathrm{OSI}=0.02$

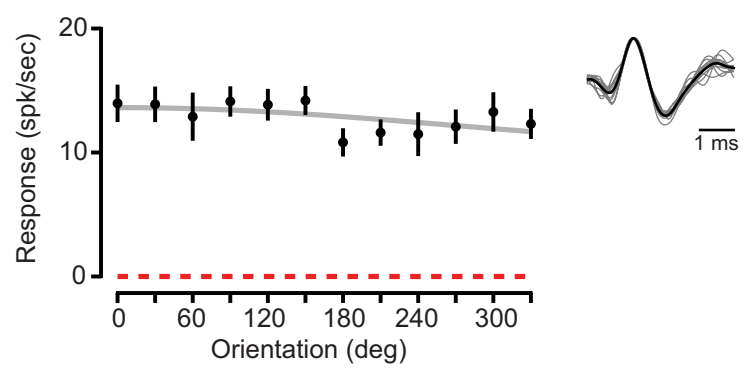

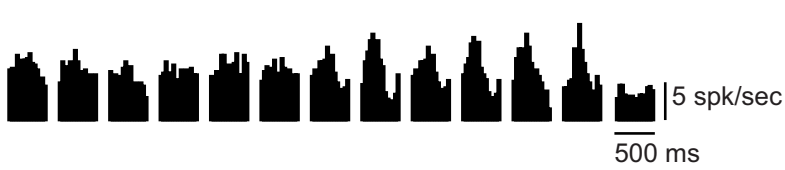

$\mathrm{OSI}=0.05$
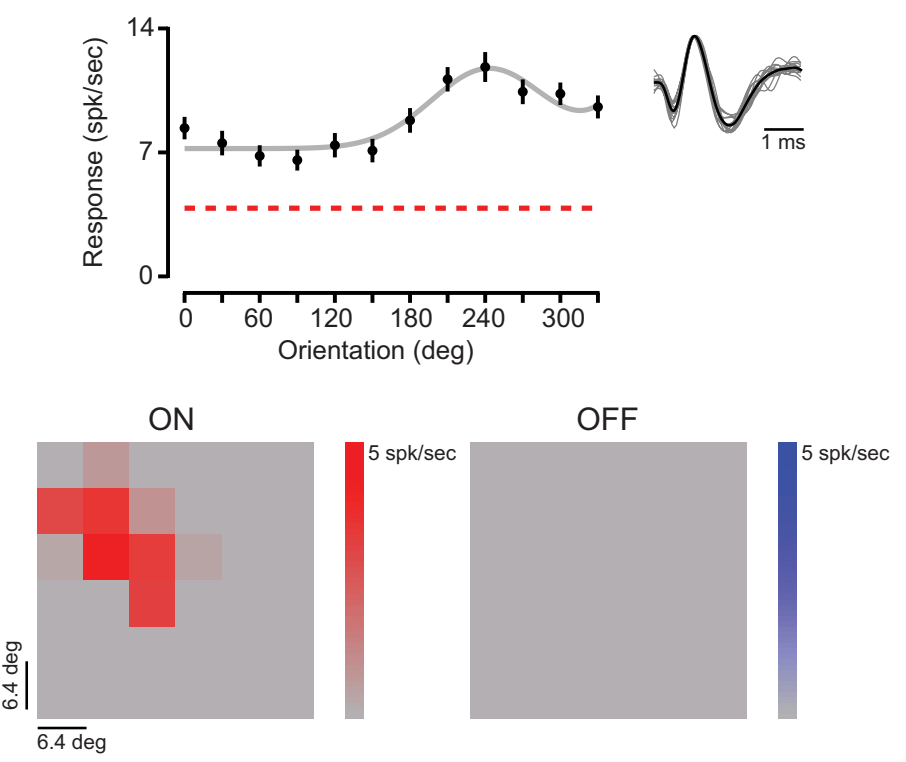

Figure 2. Orientation selectivity in neurons of the mouse LGN. $\boldsymbol{A}$, Example of an orientation-selective relay cell in mouse LGN. Mean cycled-averaged spiking responses to drifting gratings of each orientation $\left(0-330^{\circ}\right.$ ) are shown next to spontaneous activity during blank (mean-luminance) periods. The OSI was measured from peak responses (F1+ F0), plotted for all orientations (black) with the mean spontaneous activity (red dashed line) and a Gaussian fit (gray). Sample waveforms for this isolated neuron are also shown. $\boldsymbol{B}$, Example of a nonselective cell. $\boldsymbol{C}$, Another example of a selective neuron which is direction selective, has high spontaneous firing rate, and lower spike rate for peak responses. $\boldsymbol{D}$, Example of an orientation-biased cell with large spontaneous activity. $\boldsymbol{E}$, Example of a neuron with oriented receptive field subregions matching the selectivity measured with drifting gratings. Orientation tuning and sample isolated waveforms (left) shown alongside the mean responses to white (ON) and black (OFF) patches of 2-D sparse noise stimulus (right).

LGN can occur in the absence of any contribution from visually evoked or spontaneous cortical activity, suggesting that thalamic orientation selectivity is either inherited from retinal inputs or the result of processing within the LGN itself.

\section{Comparison of orientation selectivity across visual processing stages}

Although orientation selectivity is clearly evident in responses of mouse LGN relay cells, there may be additional processing in mouse visual cortex to generate the observed cortical orientation selectivity. To answer this question, we compared OSI values measured in neurons of mouse LGN with those measured in neurons of mouse V1 using intracellular recordings. Intracellular records provide a measure of the selectivity of synaptic input, based on subthreshold responses, as well as the selectivity of the suprathreshold activity, based on action potentials. The range of orientation selectivity found across our mouse LGN relay cell records was similar to the range of orientation selectivity found at the level of subthreshold membrane 
A
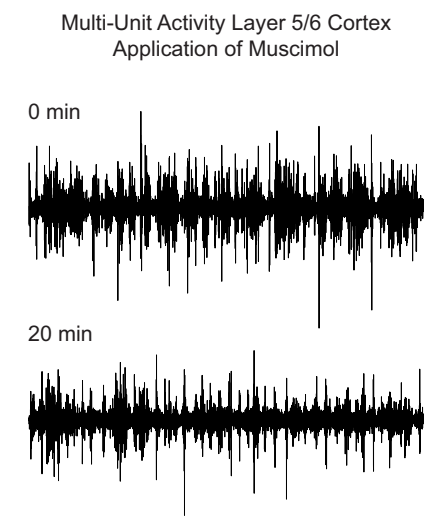

$40 \mathrm{~min}$

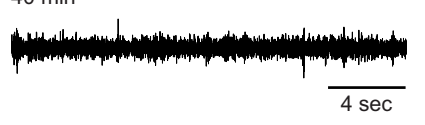

B
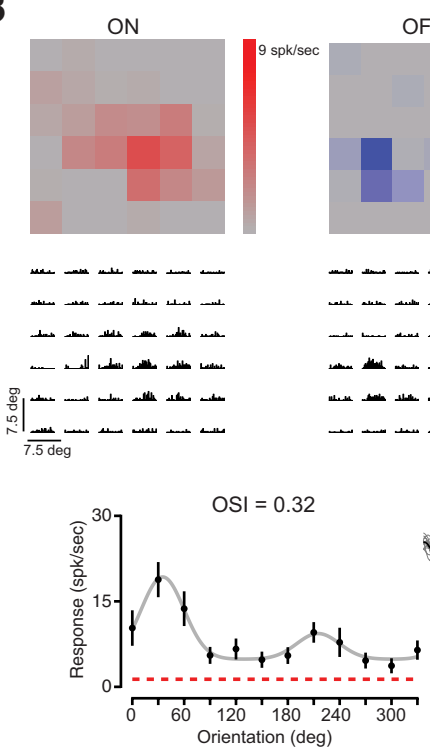

C
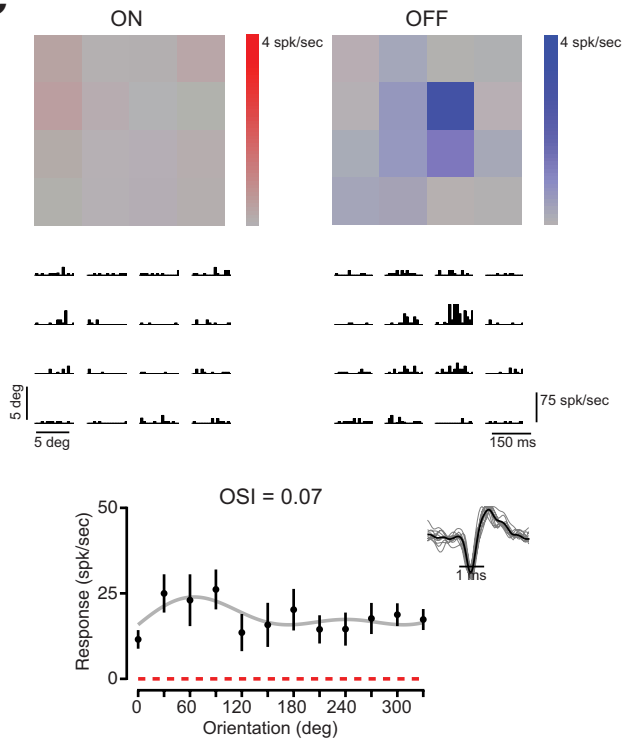

Figure 3. Orientation selectivity of mouse $L G N$ relay cells is unaffected by cortical inactivation. $A$, Inactivation of layer $5 / 6$ in visual cortex by application of muscimol, a $G A B A_{A}$ receptor agonist. Multiunit activity is reduced $20 \mathrm{~min}$ after application and completely abolished after $40 \mathrm{~min}$. Visually evoked activity in visual cortex was abolished after 40 min of application. $\boldsymbol{B}$, Example of an orientation-selective neuron and corresponding receptive field subregions recorded after cortical inactivation. ON and OFF subregions shown alongside recorded spiking activity to sparse noise stimuli. C, Example of a nonselective cell with a circular receptive field.

potential responses in V1 neurons ( $n=32$; Fig. $4 A$, top), although median OSI of subthreshold input to $\mathrm{V} 1$ neurons was less $\left(\mathrm{V} 1_{\mathrm{Vm}}=\right.$ 0.09 , $\mathrm{LGN}=0.15, p<0.001)$. No difference in subthreshold selectivity was observed between simple (median $=0.09, n=12$ ) and complex $($ median $=0.08, n=20)$ cells $(p=0.29)$. A comparison of LGN records to the subthreshold membrane potential responses of V1 simple cells alone yielded no differences in OSI (LGN median OSI $=0.15, V 1_{\mathrm{Vm}}$ median OSI $=0.09, p=0.11$ ). Although the degree of selectivity evident in subthreshold responses is low, our measured distribution closely matches values reported by other groups (Li et al., 2012).

In these same intracellular records, the degree of spike rate orientation selectivity was measured and found to be significantly higher than that found both in LGN relay cells (mean OSI = $0.38 \pm 0.24 \mathrm{SD}$, median $=0.37, n=21 ; p<0.001)$ and in $\mathrm{V} 1$ subthreshold input ( $p<0.001$; Fig. $4 A$, top). No differences in selectivity were evident between simple (mean $=0.31 \pm 0.14 \mathrm{SD}$, median $=0.37, n=5)$ and complex (mean $=0.29 \pm 0.18 \mathrm{SD}$, median $=0.29, n=16)$ cells $(p=0.71)$. These spike rate OSI values are consistent with those previously reported (Sohya et al., 2007; Kerlin et al., 2010). Across a larger population of extracellularly recorded V1 neurons that included both simple $(n=37)$ and complex $(n=8)$ inhibitory and excitatory neurons, modest orientation selectivity was evident (mean OSI $=0.33 \pm 0.14 \mathrm{SD}$, median $=0.33$ ). This degree of orientation selectivity was also significantly greater than both the LGN and V1 subthreshold input ( $p<0.001$ and $p<0.001$, respectively). No significant differences in OSI were found between simple (mean $=0.33 \pm$ $0.16 \mathrm{SD}$, median $=0.33, n=37)$ and complex $($ mean $=0.23 \pm$ $0.09 \mathrm{SD}$, median $=0.24, n=8)$ cells $(p=0.09)$, although there was a general trend for simple cells to show greater selectivity.

In both intracellular and extracellular spiking records, we found no significant difference in OSI between simple and complex cells, although there was a general trend for simple cells to show greater selectivity. Simple cells were found throughout cortical layers 2/3 and 4 (Niell and Stryker, 2008) and there was no relationship between recording depth and cell type [slope $=$
$-0.001 \pm 0.001 \mathrm{SE}, n=25$, bootstrapped principal component analysis (PCA)] (Sokal and Rohlf, 1995). There was also no relationship between spike rate OSI and recording depth (slope = $0.0002 \pm 0.0003 \mathrm{SE}, n=23$, bootstrapped PCA) (Sokal and Rohlf, 1995), although our sample does not contain records from deeper layers where orientation selectivity differs (Niell and Stryker, 2008). Both LGN and V1 responses in mice are generally low (LGN median peak spike rate: $14.7 \mathrm{spk} / \mathrm{s}, \mathrm{V} 1$ median peak spike rate: $14.9 \mathrm{spk} / \mathrm{s}$ ), and such low firing rates could potentially interfere with estimates of orientation selectivity. However, we found no significant relationship between the degree of orientation selectivity and the peak firing rate (spk/s) of neurons (LGN slope $=0 \pm 0.002 \mathrm{SD}, \mathrm{V} 1$ slope $=0 \pm 0.004 \mathrm{SD}$, bootstrapped PCA) (Sokal and Rohlf, 1995). To further determine whether low selectivity is related to noisy responses, we computed $95 \%$ confidence intervals of OSI (see Materials and Methods). If low selectivity were related to noisy estimates of OSI, the $95 \%$ confidence intervals should be higher for neurons with low selectivity, and yet we find more selective neurons to have larger confidence intervals (LGN slope $=8.7 \pm 6.8 \mathrm{SD}, \mathrm{V} 1$ slope $=5.4 \pm 3.4 \mathrm{SD}$, bootstrapped PCA) (Sokal and Rohlf, 1995).

Our records from different sites along the mouse visual pathway show that the degree of orientation selectivity found in the input to cortical neurons already exists at the level of the LGN relay cells, indicating that V1 orientation selectivity may therefore be inherited from the LGN rather than the result of an additional transformation (Fig. 1B). Even when restricting comparisons to V1 simple cells and relay cells, there was a clear absence of any selectivity enhancement. This lack of response transformation between the LGN and V1 was also evident in normalized orientation tuning curves from neurons across all three visual stages (Fig. 4B, top). We did find a difference between the degree of orientation selectivity in the level of membrane potential and spike rate that results from the biophysical spike threshold rectification (Anderson et al., 2000; Carandini and Ferster, 2000; Priebe and Ferster, 2008; Jia et al., 2010; Tan et al., 2011). 
A
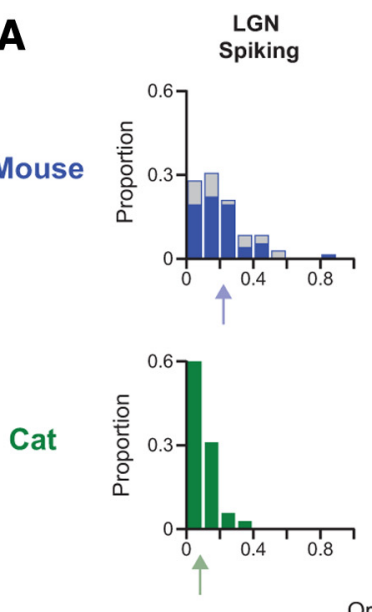
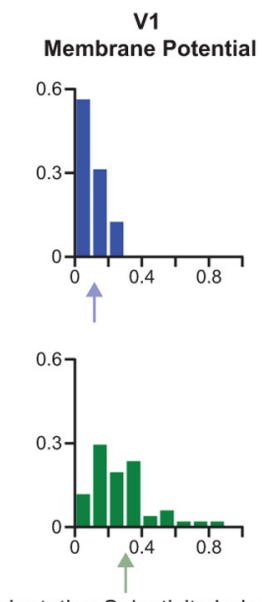

Orientation Selectivity Index (OSI)
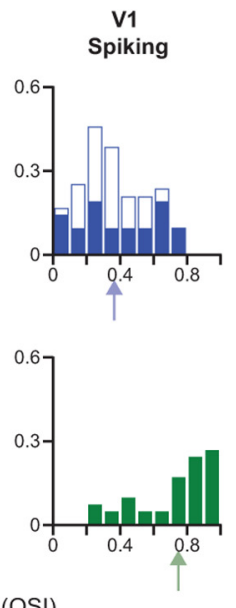
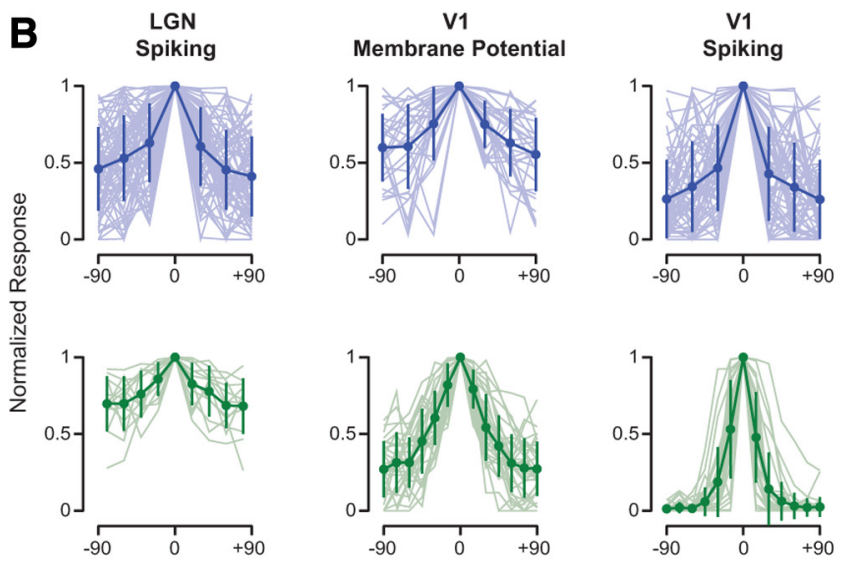

Distance from Preferred Orientation (deg)

Figure 4. Comparison of orientation selectivity in mouse and cat. $A$, Distributions of OSI in mouse (blue) and cat (green) LGN spiking responses, V1 subthreshold membrane potential responses, and V1 spiking responses. Arrows indicate mean value for each distribution. V1 spiking OSI is based on the suprathreshold responses from intracellular records. Measurements made during cortical inactivation shown for mouse (gray). In mouse V1, some of the spiking OSI measurements were based on extracellular single-unit records (open blue). OSI distributions in mouse LGN and V1 subthreshold input are similar, whereas those in the cat show an enhancement of selectivity. In V1 of both mouse and cat, there is an enhancement of selectivity from subthreshold to spiking responses. $\boldsymbol{B}$, Orientation tuning curves centered around preferred orientation $\left( \pm 90^{\circ}\right)$ are shown across the visual pathway in mouse (blue) and cat (green). Each tuning curve was normalized by the peak response at the preferred orientation. Mean and SD are plotted over each population (light shading). Note that tuning curves shown for the cat LGN are from a subset of neurons $(n=13 / 35$ ) for which we measured responses with small angle increments.

The similarity in orientation selectivity between LGN relay cells and V1 neurons in mouse led us to consider whether such similarity also exists in cat, where orientation selectivity was first described (Hubel and Wiesel, 1962). We measured the responses of cat LGN relay cells extracellularly $(n=35)$, as well as the subthreshold membrane potential and suprathreshold spiking responses of cat V1 simple cells $(n=41)$, which are predominately found in layer 4 and receive direct thalamocortical excitatory input (LeVay and Gilbert, 1976; Reid and Alonso, 1995; Ferster et al., 1996; Chung and Ferster, 1998; Usrey et al., 1999; Alonso et al., 2001). Cat LGN relay cells are known to show subtle orientation selectivity (Vidyasagar and Heide, 1984; Soodak et al., 1987; Shou and Leventhal, 1989; Thompson et al., 1994), attributed to an orientation bias in retinal ganglion cells (Boycott and Wässle, 1974; Cleland and Levick, 1974; Hammond, 1974; Levick and Thibos, 1980; Leventhal and Schall, 1983; Shou et al., 1995), and this was evident in our extracellular records (mean OSI = $0.09 \pm 0.08$, median $=0.07$; Fig. $4 A$, bottom). . Identified X-cells $(n=16)$ and Y-cells $(n=11)$ exhibited no differences in OSI $(p=0.54)$. The degree of orientation selectivity in these relay cells was less than that measured in mouse (cat LGN median OSI $=0.07, n=35$; mouse LGN median OSI $=0.15, n=72, p=$ $0.003)$. Specifically, $42 \%$ of all mouse geniculate cells were considered orientation tuned (OSI $>0.20$ ), whereas only $10 \%$ of cat geniculate cells showed the same degree of tuning. These subpopulations did not differ in median selectivity $(p=0.96)$.

In contrast to mouse $\mathrm{V} 1$ neurons, subthreshold responses in cat V1 simple cells exhibited a greater degree of orientation selectivity (mean OSI $=0.29 \pm 0.20$, median $=0.27)$ than cat LGN relay cells $(p<0.001)$ and mouse subthreshold input $(p<$ $0.001)$. As in mouse V1 neurons, a further enhancement of orientation selectivity was observed in the spiking responses of cat $\mathrm{V} 1$ neurons (mean OSI $=0.74 \pm 0.22$, median $=0.82$; Fig. $4 A$, bottom). In cat, response transformation from the LGN to V1 was also evident in normalized orientation tuning curves across all three visual stages (Fig. $4 B$, bottom). The systematic increase in orientation selectivity in the cat, from LGN relay cell responses, to subthreshold membrane potential responses, to V1 neuron spiking responses indicates a dramatic transformation across the visual pathway (Fig. $4 A, B$, bottom). In contrast, in the mouse visual pathway, a progression of increasing selectivity does not occur between the LGN and subthreshold V1 responses (Fig. $4 A, B$, top). Absence of a selectivity increase in mouse, compared with that observed in cat, suggests a fundamental difference in the processing of visual information between these two species.

\section{Discussion}

Our current understanding of neural processing in the mammalian brain has been strongly shaped by the characterization and subsequent analysis of neuronal response selectivities for specific stimulus features along the visual pathway, primarily relying on the visual systems of lagomorphs, carnivores, and primates. Today, the rodent visual system has become the focus of much investigation, given its compatibility with sophisticated genetic and imaging techniques, despite less transparency into its visual processing mechanics. How similar is the rodent model to the historical models, and how readily can we overlay our current state of knowledge onto the new rodent model? Here we examined and compared the emergence of orientation selectivity along the visual pathway of mouse and cat. In the mouse, we find a similar degree of orientation selectivity in the LGN relay cells as in the subthreshold membrane potential responses of V1 neurons (Fig. 4A, top). LGN relay cell orientation selectivity persisted even after cortical inactivation, indicating that cortical feedback connections are not the source of the selectivity (Fig. 3). Our results provide no evidence for a dramatic transformation in orientation selectivity between the LGN and V1 of the mouse (Fig. $4 A, B$, top). In striking contrast, in the cat, there is a dramatic transformation in orientation selectivity between the LGN relay cells and their cortical targets (Fig. 4A,B, bottom). Cat LGN cells display weak orientation selectivity, whereas subthreshold membrane potential responses in V1 show greater selectivity. In both the mouse and cat, cortical neuron subthreshold orientation selectivity was enhanced by spike threshold to generate greater spiking selectivity. In summary, although orientation selectivity exists in V1 of both rodents and carnivores, our results demonstrate that its generation, and thus the underlying neuronal circuitry, are distinct. 
Not only is there a difference in the emergence of orientation selectivity between mouse and cat, but the functional cortical organization in each species is distinct (Fig. 5). In cat V1, orientation selectivity is organized in a columnar fashion (Hubel and Wiesel, 1963), whereas in mouse V1 no such organization is evident (Ohki et al., 2005). Even in the gray squirrel, a highly visual rodent with strong cortical orientation selectivity, no clear functional organization for orientation selectivity exists in V1 (Heimel et al., 2005). Lagomorphs, similar to rodents, lack an orientation map in visual cortex, although a clustering of orientation preferences in neurons has been reported (Chow et al., 1971; Murphy and Berman, 1979) (Fig. 5). Primates, similar to carnivores and in contrast to rodents and lagomorphs, exhibit both strong cortical orientation selectivity and clear orientation selectivity map (Hubel and Wiesel, 1968; Essen and Zeki, 1978; Ts'o et al., 1990; Bosking et al., 1997), although the emergence of orientation selectivity within cortex differs between primate species (Fitzpatrick, 1996) (Fig. 5). Additionally, similar to carnivores, some species of primates have subpopulations of LGN relay cells that exhibit orientation selectivity (Smith et al., 1990; Xu et al., 2002; Cheong et al., 2013) (Fig. 5). The presence of orientation selectivity in primate koniocellular neurons suggests that a specific subcortical pathway transmits orientation selective signals as we find in many mouse LGN cells, although the relationship between primate koniocellular neurons and rodent or cat LGN cells is unclear.

Although the Hubel and Wiesel feedforward model has elegantly described the emergence of cat cortical orientation selectivity, the mechanisms underlying subcortical orientation selectivity are less clear. It is possible that subcortical orientation selectivity in the mouse could stem either from processing within the retina (Weng et al., 2005; Elstrott et al., 2008), or from interactions within the LGN (Levick et al., 1969). In the rabbit, for example, a subset of retinal ganglion cells (RGCs) are known to be sensitive to horizontally and vertically oriented stimuli (Barlow et al., 1964; Levick, 1967; Stewart et al., 1971), and the emergence of this property depends on an interplay between synaptic excitation and inhibition (Taylor et al., 2000; Venkataramani and Taylor, 2010). Although these RGCs prefer only horizontal or vertical orientations, selectivities for all orientations are present in rabbit V1 (Chow et al., 1971), though a bias for horizontal and vertical persists (Murphy and Berman, 1979). As in lagomorphs, retinal orientation selectivity has been observed in rodents (Weng et al., 2005; Elstrott et al., 2008; Girman and Lund, 2010), but it is unclear exactly how excitation and inhibition combine to generate the selectivity, although recent work has suggested that a developmentally driven asymmetric synaptic wiring between starburst amacrine cells and RGCs drives direction tuning (Wei et al., 2011). An additional factor contributing to retinal orienta-
LGN Visual Cortex Layer $4 \quad$ Layer $2 / 3$
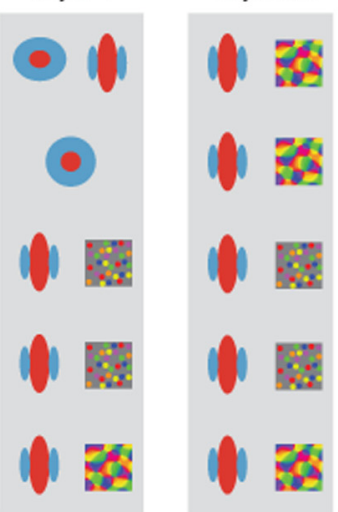

Macaque

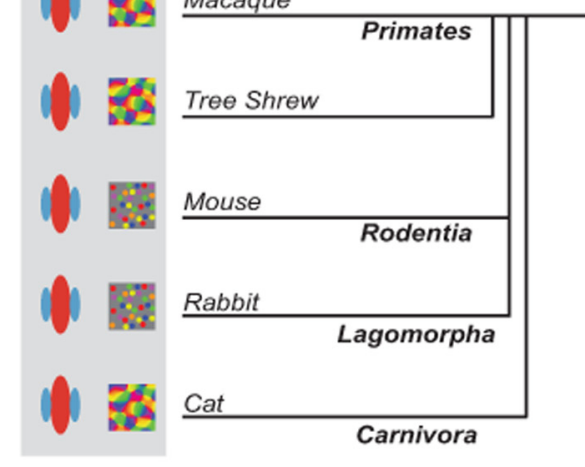

$\therefore$ Random/custered selecitvity Columnar organization

\section{急}

Figure 5. Comparison of orientation selectivity emergence across mammalian species. Orientation selectivity emerges in the 1975; Metinetal., 1988; Ohki et al., 2005; Weng et al., 2005; Ohki and Reid, 2007; Elstrott et al., 2008; Marshel et al., 2012; Piscopo primates than lagomorphs or rodents, they are not considered primates and the phylogenetic relationships remain unresolved (Cronin and Sarich, 1980; Luckett, 1980; MacPhee, 1993).

tion selectivity across mammals is the radial bias in dendritic structure of RGCs (Boycott and Wässle, 1974; Cleland and Levick, 1974; Hammond, 1974; Levick and Thibos, 1980; Leventhal and Schall, 1983; Shou et al., 1995; Weng et al., 2005). During development the retina grows outward and stretches RGC dendrites in a radial fashion, creating systematic orientation preferences in RGC responses. This radial bias, coupled with synaptic mechanisms for horizontal and vertical orientation selectivity, could provide signals driving orientation selective responses that we observed in mouse LGN relay cells (Fig. $1 B, C$ ). In addition, within the thalamus multiple RGCs may converge onto a single target relay cell (Levick et al., 1969). Any spatial offset of convergent RGC inputs would create a bias in orientation selectivity in the fashion suggested by Hubel and Wiesel (1962) (Fig. 1A).

In contrast to the mouse, orientation selectivity in the cat increases dramatically in V1 relative to LGN relay cells, but the weak orientation selectivity and orientation biases evident in relay cells may nonetheless provide essential signals for the generation or modulation of cortical orientation selectivity. Those biases may underlie a known overrepresentation of horizontal and vertical preferences and the organization of orientation selectivity within V1 (Kaschube et al., 2010; Schall, 2011). Further, although the orientation selectivity of synaptic inputs is not altered by cortical inactivation (Ferster et al., 1996; Chung and Ferster, 1998), that oriented input could arise both from summa- 
tion of spatially offset LGN relay cell receptive fields as well as the orientation biases of the relay cells themselves (Fig. 1C). Consistent with this hypothesis, the spatial polarity of LGN relay cells matches that of target cortical cells (Reid and Alonso, 1995; Alonso et al., 2001), but recent evidence indicates that the spatial offsets of relay cells are not sufficient to account fully for cortical orientation selectivity (Kuhlmann and Vidyasagar, 2011; Viswanathan et al., 2011; Stanley et al., 2012). Therefore, the spatial offset of LGN relay cell receptive fields and their orientation biases could combine synergistically to generate cortical orientation selectivity.

There are many possible combinations of receptive fields that could generate orientation selectivity, including randomly distributed inputs (Hansel and Van Vreeswijk, 2012) or oriented receptive fields spatially aligned to generate a distinct orientation selectivity. The presence of subcortical orientation selectivity strongly suggests feedforward inheritance in generating cortical selectivity, but it is possible for this selectivity to be discarded and regenerated within V1. Simultaneous recordings from connected LGN-V1 pairs, as done in the cat (Reid and Alonso, 1995; Alonso et al., 2001), would be able to distinguish between these possibilities. Although it is remains unknown which mechanism explains the observed cortical orientation selectivity, we have demonstrated its emergence along the visual pathway is distinct between mice and cats.

The emergence of orientation selectivity in V1 is considered the classic example of a computation performed by the cerebral cortex. In carnivores, cortical orientation selectivity clearly emerges from less selective LGN relay cell inputs, even when the LGN relay cell inputs are forced to innervate auditory cortex instead of visual cortex (Sharma et al., 2000; Von Melchner et al., 2000). The presence of orientation selectivity in V1 of every mammal in which it has been measured has supported the idea that its emergence reflects a fundamental function of neocortex. Here we demonstrate that despite consistency across mammalian visual systems, the underlying mechanisms for emergence of response selectivity are not the same from species to species. Like the differences we have shown here between mouse and cat, it is also known that orientation selectivity emerges at different stages in cat and monkey (Fig. 5). In the cat, orientation selectivity is apparent in the thalamorecipient layer 4 neurons (Hubel and Wiesel, 1962), whereas in the monkey and tree shrew it emerges in layer 2/3 (Hubel and Wiesel, 1968; Essen and Zeki, 1978; Blasdel and Fitzpatrick, 1984; Schall et al., 1986; Smith et al., 1990; Ts'o et al., 1990; Chisum et al., 2003; Gur et al., 2005) (Fig. 5).

The differences in the emergence of orientation selectivity cannot be simply ascribed to the evolutionary ancestral relationship between mammals, particularly because rodents are more closely related to primates than carnivores. Many additional factors may play a role in determining at which stage orientation selectivity first emerges. Notably, cats and macaques are predators, whereas mice are herbivores. The lateralization of the eyes, the presence or absence of a fovea, the degree to which animals are nocturnal or diurnal, and the reliance on vision may play important roles in determining the emergence and organization of orientation selectivity. We suggest that despite the ubiquity of cortical orientation selectivity, a diversity of mechanisms exists for its generation.

\section{References}

Alonso JM, Usrey WM, Reid RC (2001) Rules of connectivity between geniculate cells and simple cells in cat primary visual cortex. J Neurosci 21:4002-4015. Medline
Anderson J, Lampl I, Reichova I, Carandini M, Ferster D (2000) Stimulus dependence of two-state fluctuations of membrane potential in cat visual cortex. Nat Neurosci 3:617-621. CrossRef Medline

Barlow HB, Hill RM, Levick WR (1964) Retinal ganglion cells responding selectively to direction and speed of image motion in the rabbit. J Physiol 173:377-407. Medline

Blasdel GG, Fitzpatrick D (1984) Physiological organization of layer 4 in macaque striate cortex. J Neurosci 4:880-895. Medline

Bosking WH, Zhang Y, Schofield B, Fitzpatrick D (1997) Orientation selectivity and the arrangement of horizontal connections in tree shrew striate cortex. J Neurosci 17:2112-2127. Medline

Boycott BB, Wässle H (1974) The morphological types of ganglion cells of the domestic cat's retina. J Physiol 240:397-419. Medline

Brainard DH (1997) The psychophysics toolbox. Spat Vis 10:433-436. CrossRef Medline

Carandini M, Ferster D (2000) Membrane potential and firing rate in cat primary visual cortex. J Neurosci 20:470-484. Medline

Cheong SK, Tailby C, Solomon SG, Martin PR (2013) Cortical-like receptive fields in the lateral geniculate nucleus of marmoset monkeys. J Neurosci 33:6864-6876. CrossRef Medline

Chisum HJ, Mooser F, Fitzpatrick D (2003) Emergent properties of layer $2 / 3$ neurons reflect the collinear arrangement of horizontal connections in tree shrew visual cortex. J Neurosci 23:2947-2960. Medline

Chow KL, Masland RH, Stewart DL (1971) Receptive field characteristics of striate cortical neurons in the rabbit. Brain Res 33:337-352. CrossRef Medline

Chung S, Ferster D (1998) Strength and orientation tuning of the thalamic input to simple cells revealed by electrically evoked cortical suppression. Neuron 20:1177-1189. CrossRef Medline

Cleland BG, Levick WR (1974) Properties of rarely encountered types of ganglion cells in the cat's retina and an overall classification. J Physiol 240:457-492. Medline

Cronin JE, Sarich VM (1980) Tupaiid and archonta phylogeny: the macromolecular evidence. In: Comparative biology and evolutionary relationships of tree shrews, pp 293-312. New York: Plenum.

Douglas RJ, Martin KA (2004) Neuronal circuits of the neocortex. Annu Rev Neurosci 27:419-451. CrossRef Medline

Douglas RJ, Martin KAC, Whitterridge D (1989) A canonical microcircuit for neocortex. Neural Comp 1:480-488. CrossRef

Dräger UC (1975) Receptive fields of single cells and topography in mouse visual cortex. J Comp Neurol 160:269-290. CrossRef Medline

Elstrott J, Anishchenko A, Greschner M, Sher A, Litke AM, Chichilnisky EJ, Feller MB (2008) Direction selectivity in the retina is established independent of visual experience and cholinergic retinal waves. Neuron 58 : 499-506. CrossRef Medline

Essen DC, Zeki SM (1978) The topographic organization of rhesus monkey prestriate cortex. J Physiol 277:193-226. Medline

Ferster D, Chung S, Wheat H (1996) Orientation selectivity of thalamic input to simple cells of cat visual cortex. Nature 380:249-252. CrossRef Medline

Fitzpatrick D (1996) The functional organization of local circuits in visual cortex: insights from the study of tree shrew striate cortex. Cereb Cortex 6:329-341. CrossRef Medline

Gao E, DeAngelis GC, Burkhalter A (2010) Parallel input channels to mouse primary visual cortex. J Neurosci 30:5912-5926. CrossRef Medline

Gardner JL, Anzai A, Ohzawa I, Freeman RD (1999) Linear and nonlinear contributions to orientation tuning of simple cells in the cat's striate cortex. Vis Neurosci 16:1115-1121. CrossRef Medline

Girman S, Lund R (2010) Orientation-specific modulation of rat retinal ganglion cell responses and its dependence on relative orientations of the center and surround gratings. J Neurophysiol 104:2951-2962. CrossRef Medline

Grubb MS, Thompson ID (2003) Quantitative characterization of visual response properties in the mouse dorsal lateral geniculate nucleus. J Neurophysiol 90:3594-3607. CrossRef Medline

Gur M, Kagan I, Snodderly DM (2005) Orientation and direction selectivity of neurons in V1 of alert monkeys: functional relationships and laminar distributions. Cereb Cortex 15:1207-1221. CrossRef Medline

Hammond P (1974) Cat retinal ganglion cells: size and shape of receptive field centres. J Physiol 242:99-118. Medline

Hansel D, van Vreeswijk C (2012) The mechanism of orientation selectivity 
in primary visual cortex without a functional map. J Neurosci 32:40494064. CrossRef Medline

Heimel JA, Van Hooser SD, Nelson SB (2005) Laminar organization of response properties in primary visual cortex of the gray squirrel (Sciurus carolinensis). J Neurophysiol 94:3538 -3554. CrossRef Medline

Hochstein S, Shapley RM (1976) Linear and nonlinear spatial subunits in Y cat retinal ganglion cells. J Physiol 262:265-284. Medline

Hubel DH, Wiesel TN (1959) Receptive fields of single neurones in the cat's striate cortex. J Physiol 148:574-591. Medline

Hubel DH, Wiesel TN (1961) Integrative action in the cat's lateral geniculate body. J Physiol 155:385-398. Medline

Hubel DH, Wiesel TN (1962) Receptive fields, binocular interaction and functional architecture in the cat's visual cortex. J Physiol 160:106-154. Medline

Hubel DH, Wiesel TN (1963) Shape and arrangement of columns in cat's striate cortex. J Physiol 165:559-568. Medline

Hubel DH, Wiesel TN (1968) Receptive fields and functional architecture of monkey striate cortex. J Physiol 195:215-243. Medline

Jia H, Rochefort NL, Chen X, Konnerth A (2010) Dendritic organization of sensory input to cortical neurons in vivo. Nature 464:1307-1312. CrossRef Medline

Kaschube M, Schnabel M, Löwel S, Coppola DM, White LE, Wolf F (2010) Universality in the evolution of orientation columns in the visual cortex. Science 330:1113-1116. CrossRef Medline

Kerlin AM, Andermann ML, Berezovskii VK, Reid RC (2010) Broadly tuned response properties of diverse inhibitory neuron subtypes in mouse visual cortex. Neuron 67:858-871. CrossRef Medline

Kuhlmann L, Vidyasagar TR (2011) A computational study of how orientation bias in the lateral geniculate nucleus can give rise to orientation selectivity in primary visual cortex. Front Syst Neurosci 5:81. Medline

LeVay S, Gilbert CD (1976) Laminar patterns of geniculocortical projection in the cat. Brain Res 113:1-19. CrossRef Medline

Leventhal AG, Schall JD (1983) Structural basis of orientation sensitivity of cat retinal ganglion cells. J Comp Neurol 220:465-475. CrossRef Medline

Levick WR (1967) Receptive fields and trigger features of ganglion cells in the visual streak of the rabbits retina. J Physiol 188:285-307. Medline

Levick WR, Thibos LN (1980) Orientation bias of cat retinal ganglion cells. Nature 286:389-390. CrossRef Medline

Levick WR, Oyster CW, Takahashi E (1969) Rabbit lateral geniculate nucleus: sharpener of directional information. Science 165:712-714. CrossRef Medline

Li YT, Ma WP, Pan CJ, Zhang LI, Tao HW (2012) Broadening of cortical inhibition mediates developmental sharpening of orientation selectivity. J Neurosci 32:3981-3991. CrossRef Medline

Luckett WP (1980) The suggested evolutionary relationships and classification of tree shrews. In: Comparative biology and evolutionary relationships of tree shrews, pp 3-31. New York: Plenum.

MacPhee RDE (1993) Primates and their relatives in phylogenetic perspective. New York: Plenum.

Marshel JH, Kaye AP, Nauhaus I, Callaway EM (2012) Anterior-posterior direction opponency in the superficial mouse lateral geniculate nucleus. Neuron 76:713-720. CrossRef Medline

Métin C, Godement P, Imbert M (1988) The primary visual cortex in the mouse: receptive field properties and functional organization. Exp Brain Res 69:594-612. Medline

Murphy EH, Berman N (1979) The rabbit and the cat: a comparison of some features of response properties of single cells in the primary visual cortex. J Comp Neurol 188:401-427. CrossRef Medline

Niell CM, Stryker MP (2008) Highly selective receptive fields in mouse visual cortex. J Neurosci 28:7520-7536. CrossRef Medline

Ohki K, Chung S, Ch'ng YH, Kara P, Reid RC (2005) Functional imaging with cellular resolution reveals precise micro-architecture in visual cortex. Nature 433:597-603. CrossRef Medline

Ohki K, Reid RC (2007) Specificity and randomness in the visual cortex. Curr Opin Neurobiol 17:401-407. CrossRef Medline

Pelli DG (1997) The VideoToolbox software for visual psychophysics: transforming numbers into movies. Spat Vis 10:437-442. CrossRef Medline

Piscopo DM, El-Danaf RN, Huberman AD, Niell CM (2013) Diverse visual features encoded in mouse lateral geniculate nucleus. J Neurosci 33:46424656. CrossRef Medline

Priebe NJ (2008) The relationship between subthreshold and suprath- reshold ocular dominance in cat primary visual cortex. J Neurosci 28:8553-8559. CrossRef Medline

Priebe NJ, Ferster D (2008) Inhibition, spike threshold, and stimulus selectivity in primary visual cortex. Neuron 57:482-497. CrossRef Medline

Reid RC, Alonso JM (1995) Specificity of monosynaptic connections from thalamus to visual cortex. Nature 378:281-284. CrossRef Medline

Ringach DL, Shapley RM, Hawken MJ (2002) Orientation selectivity in macaque V1: diversity and laminar dependence. J Neurosci 22:5639-5651. Medline

Runyan CA, Schummers J, Van Wart A, Kuhlman SJ, Wilson NR, Huang ZJ, Sur M (2010) Response features of parvalbumin-expressing interneurons suggest precise roles for subtypes of inhibition in visual cortex. Neuron 67:847-857. CrossRef Medline

Schall JD (2011) An alternative hypothesis for orientation columns in the visual cortex. Science. Online publication.

Schall JD, Perry VH, Leventhal AG (1986) Retinal ganglion cell dendritic fields in old-world monkeys are oriented radially. Brain Res 368:18-23. CrossRef Medline

Sharma J, Angelucci A, Sur M (2000) Induction of visual orientation modules in auditory cortex. Nature 404:841-847. CrossRef Medline

Shou TD, Leventhal AG (1989) Organized arrangement of orientationsensitive relay cells in the cat's dorsal lateral geniculate nucleus. J Neurosci 9:4287-4302. Medline

Shou T, Leventhal AG, Thompson KG, Zhou Y (1995) Direction biases of X and $Y$ type retinal ganglion cells in the cat. J Neurophysiol 73:1414-1421. Medline

Sillito AM, Jones HE, Gerstein GL, West DC (1994) Feature-linked synchronization of thalamic relay cell firing induced by feedback from the visual cortex. Nature 369:479-482. CrossRef Medline

Smith EL 3rd, Chino YM, Ridder WH 3rd, Kitagawa K, Langston A (1990) Orientation bias of neurons in the lateral geniculate nucleus of macaque monkeys. Vis Neurosci 5:525-545. CrossRef Medline

Sohya K, Kameyama K, Yanagawa Y, Obata K, Tsumoto T (2007) GABAergic neurons are less selective to stimulus orientation than excitatory neurons in layer II/III of visual cortex, as revealed by in vivo functional $\mathrm{Ca}^{2+}$ imaging in transgenic mice. J Neurosci 27:2145-2149. CrossRef Medline

Sokal RR, and Rohlf FJ (1995) The principles and practice of statistics in biological research, Ed 4. New York:Freeman.

Soodak RE, Shapley RM, Kaplan E (1987) Linear mechanism of orientation tuning in the retina and lateral geniculate nucleus of the cat. J Neurophysiol 58:267-275. Medline

Stanley GB, Jin J, Wang Y, Desbordes G, Wang Q, Black MJ, Alonso JM (2012) Visual orientation and directional selectivity through thalamic synchrony. J Neurosci 32:9073-9088. CrossRef Medline

Stewart DL, Chow KL, Masland RH (1971) Receptive-field characteristics of lateral geniculate neurons in the rabbit. J Neurophysiol 34:139-147. Medline

Tan AY, Brown BD, Scholl B, Mohanty D, Priebe NJ (2011) Orientation selectivity of synaptic input to neurons in mouse and cat primary visual cortex. J Neurosci 31:12339-12350. CrossRef Medline

Taylor WR, He S, Levick WR, Vaney DI (2000) Dendritic computation of direction selectivity by retinal ganglion cells. Science 289:2347-2350. CrossRef Medline

Thompson KG, Zhou Y, Leventhal AG (1994) Direction-sensitive X and Y cells within the A laminae of the cat's LGNd. Vis Neurosci 11:927-938. CrossRef Medline

Ts'o DY, Frostig RD, Lieke EE, Grinvald A (1990) Functional organization of primate visual cortex revealed by high resolution optical imaging. Science 249:417-420. CrossRef Medline

Usrey WM, Reppas JB, Reid RC (1999) Specificity and strength of retinogeniculate connections. J Neurophysiol 82:3527-3540. Medline

Venkataramani S, Taylor WR (2010) Orientation selectivity in rabbit retinal ganglion cells is mediated by presynaptic inhibition. J Neurosci 30:15664-15676. CrossRef Medline

Vidyasagar TR, Heide W (1984) Geniculate orientation biases seen with moving sine wave gratings: implications for a model of simple cell afferent connectivity. Exp Brain Res 57:176-200. Medline

Viswanathan S, Jayakumar J, Vidyasagar TR (2011) Role of feedforward geniculate inputs in the generation of orientation selectivity in the cat's primary visual cortex. J Physiol 589:2349-2361. CrossRef Medline

von Melchner L, Pallas SL, Sur M (2000) Visual behaviour mediated by retinal 
projections directed to the auditory pathway. Nature 404:871-876. CrossRef Medline

Wagor E, Mangini NJ, Pearlman AL (1980) Retinotopic organization of striate and extrastriate visual cortex in the mouse. J Comp Neurol 193: 187-202. CrossRef Medline

Wei W, Hamby AM, Zhou K, Feller MB (2011) Development of asymmetric inhibition underlying direction selectivity in the retina. Nature 469:402-406. CrossRef Medline
Weng S, Sun W, He S (2005) Identification of ON-OFF direction-selective ganglion cells in the mouse retina. J Physiol 562:915-923. CrossRef Medline

Xu X, Ichida J, Shostak Y, Bonds AB, Casagrande VA (2002) Are primate lateral geniculate nucleus (LGN) cells really sensitive to orientation or direction? Vis Neurosci 19:97-108. CrossRef Medline 